\title{
O tratamento da informação no design de catálogos técnicos impressos
}

\author{
Treating information in designing printed technical catalogues
}

Sandra M. R. de Souza, Maria Regina L. Schmid

design da informação, comunicação técnica, catálogo técnico, design de catálogos

O catálogo técnico é uma forma de comunicação com objetivos informacionais e comerciais. É responsável por apresentar aos seus usuários conteúdos e instruções técnicas claras e seguras, paralelamente à sua função de atender aos interesses de uma corporação na divulgação de produtos, marcas ou tecnologias. Utilizando conceitos e princípios do design da informação, apresentamos, neste artigo, critérios para a avaliação das páginas impressas de catálogos técnicos, levando em consideração o equilíbrio entre três fatores que, combinados em diferentes proporções, devem qualificar qualquer produto de design: utilidade, satisfação e confiabilidade. Destacamos que o desenvolvimento da comunicação por profissionais tecnicamente preparados, aliado aos recursos advindos do design da informação, pode resultar em materiais capazes de integrar os requisitos informativos e éticos da comunicação técnica, aos apelos persuasivos da comunicação comercial.

information design, technical communication, document design, catalogue design

Technical catalogues are a form of communication that has informational and commercial objectives. They are responsible for presenting clear, safe technical content and instructions to their users, parallelly to meeting the corporation's interests in divulging products, brands or technologies. Using information design concepts and principles, in this article we will present criteria for the assessment of printed technical catalogue pages, considering the balance among three factors which, combined in different proportions, must qualify any design product: utility, satisfaction and reliability. We emphasize that the development of communications by technically prepared professionals, allied to resources coming from information design, can result in materials that are capable of blending the informative and ethical requirements of technical communications with the persuasive appeals of commercial communications.

\section{A natureza da comunicação técnica e as funções do catálogo técnico}

A comunicação técnica é uma disciplina que surgiu com o crescente desenvolvimento da tecnologia e a consequente necessidade de divulgação de sua terminologia, recursos e possibilidades de aplicação. O seu princípio geral considera que a tecnologia é mais do que o desenvolvimento de produtos, equipamentos e sistemas, envolvendo também processos para tornar acessível o seu uso correto. Cabe aos comunicadores técnicos facilitar a transferência de informações, desenvolvendo habilidades e conhecimento para introduzir novos usuários a uma determinada tecnologia disponibilizada comercial ou gratuitamente.

Praticar a comunicação técnica com eficiência pode ser tarefa simples, quando se pensa em materiais que somente cumprem o papel de apresentar informações. Porém, fazê-la do ponto de vista do design da informação, preocupando-se não somente com o conteúdo, mas com o conjunto formado pelo conteúdo do material e as necessidades tanto de seu produtor/emissor, como de seu receptor/intérprete, é tarefa complexa. O processo todo está sujeito a obstáculos diversos que podem causar problemas na comunicação e comprometer o resultado final desejado ao material.

Constituem manifestações de comunicação técnica, os catálogos, os manuais de procedimento e os guias de referência, entre outros. Esses três tipos básicos têm em comum um objetivo instrucional que possibilita uma ação posterior ou simultânea à sua leitura; porém, cada um deles apresenta atributos bem definidos que os distinguem entre si.

Os manuais de procedimento são tutoriais que orientam comportamentos e ensinam como desenvolver atividades e procedimentos específicos, tais como uso adequado de produtos, 
instalação de equipamentos, política de organizações, administração de sistemas e solução de problemas. São destinados a usuários diversos e visam habilitá-los a desenvolver uma tarefa de imediato.

Os guias de referência são documentos para consultas rápidas, que objetivam fornecer lembretes e conceitos rápidos ou ajuda ao usuário sobre um item específico na atividade que está sendo desenvolvida. Sua eficácia depende de um estilo de escrita ou de visualização extremamente conciso, no qual pode ser incluído o uso de siglas, códigos ou ícones para identificação rápida de itens.

Os catálogos fornecem informações sobre produtos ou serviços disponibilizados por uma organização e podem ser direcionados tanto para atividades prévias à venda de um produto ou serviço quanto ao suporte técnico na fase de pós-venda do bem.

O catálogo técnico é um tipo de comunicação técnica que merece atenção especial dos designers da informação, pois apresenta a característica de ser, ao mesmo tempo, uma manifestação pura de comunicação técnica, cujo objetivo principal é possibilitar a compreensão sobre como o uso de produtos originados pelo desenvolvimento tecnológico pode ser feito de forma segura e eficiente, e uma ferramenta de marketing institucional, cuja finalidade precípua é a de contribuir para a construção de uma imagem confiável e superior da empresa e dos produtos que oferece ao mercado.

De acordo com Cliff (1994:6) o surgimento de catálogos como manifestação de comunicação se deu durante o século XV e só assumiu o formato que conhecemos hoje no século XIX. O autor comenta que, na época do seu surgimento, a credibilidade dos catálogos era alta, pois em muitos casos, eles e a Bíblia eram os únicos materiais de leitura de famílias residentes em fazendas, comuns naquele período. Os catálogos eram importantes para divulgar novos equipamentos mecanizados para o aumento de produtividade nas fazendas, acabando por se transformar, também, em material de leitura corrente nas escolas de comunidades rurais.

Atualmente, sua manifestação pode se dar em suportes jamais imaginados quando os primeiros catálogos foram concebidos. Como exemplo, citamos os catálogos eletrônicos disponibilizados na internet, que além de poderem ser acessados praticamente no mundo inteiro e a qualquer hora, podem, em alguns casos, ser utilizados de forma interativa pelo usuário para a seleção exclusiva do conteúdo que lhe interessa no momento.

Mesmo tendo seus suportes de manifestação constantemente atualizados, os catálogos mantêm a mesma essência para a qual foram criados: apresentar produtos e tecnologias e tornálos acessíveis a diferentes usuários. "O papel do catálogo não mudou muito, mesmo com o advento da tecnologia moderna. O catálogo ainda nos leva a um mundo que não podemos visitar, para vender produtos que não podemos ver - transformando a caixa postal de todos em uma loja de departamentos de sonhos." (Cliff, 1994:9).

O catálogo técnico, no entanto, é um pouco mais específico do que esse catálogo genérico, concebido com a função principal de apresentar produtos. O seu maior diferencial está no fato dele ter basicamente o objetivo de divulgar informações que vão além da simples apresentação de produtos. Normalmente, constitui-se em um documento que fornece informações técnicas sobre produtos ou serviços disponibilizados por uma organização, comumente incluindo requisitos, procedimentos e consequências do seu funcionamento. Além disso, o catálogo técnico tem também uma responsabilidade comercial, constituindo-se em um possível instrumento de marketing corporativo, uma vez que a sua representação física costuma apresentar espaço suficiente para a divulgação de marcas e dados institucionais.

Como meio de comunicação, o catálogo técnico possui basicamente dois agentes principais, um que recebe informações e outro que as divulga. Um dos agentes é o próprio usuário do material, aquele que o acessa com o objetivo de se instruir, em busca de informações técnicas sobre um produto - ele necessita do conteúdo do material. Sua satisfação, com relação ao catálogo, está relacionada à capacidade do mesmo em apresentar descrições técnicas de produtos, tais como requisitos e informações sobre o seu funcionamento, aplicações e demais procedimentos relacionados ao produto. $\mathrm{O}$ uso de recursos visuais é bem-vindo para facilitar a manipulação do material pelo usuário, assim como facilitar-Ihe o acesso e a compreensão das informações e explicações técnicas sobre os produtos divulgados.

O outro agente é o solicitante do material ao comunicador, ou seja, a instituição que usa o catálogo como uma ferramenta para divulgar seus produtos e tecnologias e agilizar o processo de venda. Sua satisfação, com relação ao catálogo, está relacionada à capacidade dele apresentar 
características que proporcionem confiabilidade à empresa e ao produto, dentro dos padrões de qualidade desejados pela instituição. $O$ uso de recursos visuais é bem-vindo para facilitar a aplicação de técnicas persuasivas na promoção de produtos e na exposição de suas marcas visando conquistar o usuário.

Assim, a realidade do catálogo técnico encontra-se entre dois referenciais: um técnico, responsável pela transmissão do conteúdo instrucional; outro, publicitário, caracterizado pela função de valorizar a marca da empresa e, consequentemente, facilitar a venda dos produtos catalogados.

A eficácia do catálogo técnico depende da sua capacidade de atender tanto aos objetivos de comunicação técnica como aos de uma comunicação comercial. Ambos estão intrinsecamente relacionados, pois o não atendimento de um deles pode afetar o outro. Uma falha na divulgação de informações técnicas será diretamente relacionada à empresa que assina o material, podendo afetar-Ihe comercialmente. De forma similar, o uso inadequado de ferramentas de comunicação e marketing no material pode prejudicar a credibilidade do seu conteúdo técnico. Percebemos, assim, que os dois referenciais são complementares.

\section{Principais problemas no design de catálogos técnicos}

Acreditamos que os principais obstáculos possíveis de comprometer a comunicação realizada por meio de um catálogo técnico estão diretamente relacionados com os produtores/emissores do material e com a mensagem em si e, em muitos casos, podem ser evitados.

Os principais problemas no design de catálogos técnicos podem estar relacionados com alguma destas três hipóteses sobre as quais desenvolvemos nossa reflexão neste artigo:

1. Equilíbrio - Uma das grandes falhas na concepção de catálogos técnicos é o seu desenvolvimento ser feito por profissionais sem conhecimentos suficientes à produção de um material eficiente. Em alguns casos, os emissores são profissionais da comunicação que entendem bem da atividade de comunicar, porém desconhecem o assunto técnico tratado. Em outros casos, o desenvolvimento do material é feito por profissionais tecnicamente preparados sobre o assunto a ser informado, engenheiros por exemplo, porém incapacitados de expô-lo de forma comunicativa e aprazível. Em ambos os casos, o foco está mais voltado para o que o profissional sabe fazer, do que para as reais necessidades do usuário do material. Este nos parece ser o principal fator responsável por invalidar muitos catálogos que se apresentam como materiais excessivamente visuais, ou exageradamente técnicos, sem um equilíbrio adequado entre a sua apresentação estética e o seu conteúdo informativo.

2. Aspecto de propaganda - $O$ fato de muitas vezes catálogos técnicos não serem produtos comercializados, pode reduzir a atenção que é dispensada em seu desenvolvimento, do ponto de vista de uma comunicação comercial. Porém, além de ser uma forma de comunicação técnica, os catálogos são, também, uma ferramenta de marketing da corporação que os emite. Acreditamos na possibilidade deles serem criados visando tanto a ética e a informação necessárias à comunicação técnica quanto a persuasão desejada na comunicação comercial de marcas.

3. Quantidade de informação - Catálogos técnicos não precisam, necessariamente, transmitir todas as informações técnicas sobre determinado assunto. A quantidade elevada de informações pode causar tensão excessiva durante o processo de assimilação da informação pelo usuário, resultando em insatisfação e, eventualmente, na não assimilação de qualquer informação apresentada no material. Parece-nos ser mais interessante que os catálogos sirvam de diretrizes para que mais informações sobre o assunto sejam obtidas em outras fontes, de modo complementar.

Para justificarmos a necessidade de se dispensar atenção especial aos catálogos técnicos, fazemos uso dos critérios expostos por Rosenfeld e Morville (1998:11), em defesa da arquitetura da informação. Os autores justificam a existência da disciplina, relacionando-a com valores financeiros de uma organização e expõem diversos motivos da importância da disciplina, bastante relevantes para o caso da comunicação técnica, entre os quais destacamos:

- O custo para se encontrar informações em ambientes mal organizados é caro. O tempo no ambiente profissional é um bem precioso, e a sucessão de pequenos períodos extras gastos diariamente em busca de informações que existem, mas não estão claras, pode prejudicar o desempenho dos funcionários e frustrar clientes. 
- O custo por não se encontrar informações relevantes no ambiente profissional é igualmente elevado e pode resultar em decisões inadequadas, duplicação de esforços para se realizar uma tarefa, perda de clientes que não encontram informações necessárias no material da empresa, desperdício de tempo para se providenciar o suporte à ausência das informações.

- O valor da educação de clientes, ao se apresentar de forma adequada novas informações relativas aos assuntos de seu interesse, é inestimável.

- O custo para se produzir um material de comunicação é muito elevado para que ele necessite ser refeito por não ter sido bem organizado anteriormente.

- O custo do treinamento para se usar um sistema é elevado e pode ser reduzido através da sua simplificação, com informações apresentadas de forma coerente.

- O valor de uma marca não está somente associado à estética agradável apresentada por seu material de comunicação, mas também à sua eficiência em transmitir informações úteis de forma prática.

\section{A informação na comunicação técnica}

No desenvolvimento da comunicação técnica, a informação é o componente mais valioso. Porém, comunicar e informar são tarefas diferentes e complementares na exposição de um conteúdo técnico. Enquanto a tarefa de comunicar está mais relacionada à transmissão de uma mensagem com o objetivo de torná-la comum e compreensível por um número considerável de pessoas, em algum contexto sociocultural, o ato de informar está mais voltado a instruir, a educar, a possibilitar uma formação. A transmissão de informações é, sem dúvida, uma forma de comunicação, porém subentende a transferência de dados importantes aos agentes da comunicação. Esses exigem, em grande parte dos casos, pré-requisitos nos destinatários da mensagem.

Quando nos referimos à informação em catálogos técnicos, trata-se mais especificamente da informação tecnológica, concebida para divulgar e aperfeiçoar produtos, métodos e processos produtivos. É uma informação que possibilita capacitação técnica, que permite a transformação de tecnologia em bem de consumo. Desempenha um papel importante à competitividade das empresas, pois possibilita a diferenciação e, em âmbito mais amplo, facilita o desenvolvimento tecnológico das sociedades.

Para trabalhar com a informação, o comunicador necessita inicialmente acessar fontes de dados que possam originá-la. Os dados, nessa perspectiva, são somente fontes para a criação de informações, mas não um produto pronto para ser veiculado na comunicação. Para que tenham valor, é necessário que os dados sejam organizados, transformados e apresentados de forma a oferecer um significado ou alguma orientação a seus intérpretes. Essa transformação dos dados em informação útil pressupõe um trabalho intelectual baseado em critérios seletivos como relevância e propósito:

Uma vez que se tem um senso de organização, mesmo casual, você pode relaxar com aquele conhecimento e começar a examinar a informação a partir de diferentes pontos vantajosos, que irão lhe possibilitar entender a relação entre pedaços de informação. [...] Cada forma de organização irá criar uma nova estrutura. E cada nova estrutura irá lhe possibilitar enxergar um novo significado, agindo como um novo método de classificação a partir do qual um todo pode ser compreendido. (Wurman, 1990: 65-67).

Cabe ao comunicador descobrir novas formas para representar uma informação e possibilitar a sua compreensão, lembrando que a importância da informação está relacionada ao valor que ela representa para o público ou usuário-alvo. É importante, então, a adoção de critérios de organização que permitam a esse usuário-alvo identificar e hierarquizar as mensagens da forma mais eficiente, ou seja, com conforto, segurança e economia de esforços.

\section{Alguns obstáculos a serem enfrentados pela comunicação técnica}

Os problemas que, normalmente, cercam materiais de comunicação técnica giram em torno das três dimensões da mensagem: a dimensão técnica propriamente dita, que diz respeito à capacidade do material em transmitir o conteúdo técnico com exatidão e segurança; a dimensão sintático-semântica, relativa à capacidade do material de comunicar significados com satisfação e conforto estético, e a dimensão pragmática, voltada à capacidade do material influenciar as ações dos seus leitores. 
"A causa mais comum dos mal-entendidos na comunicação reside no fazer a pessoa que fala ou escreve uma suposição que, no seu entender, não precisa ser explicitada". (Parry, 1976:10-40). Outro fator que pode causar obstáculos na recepção de um material de comunicação é a quantidade excessiva de informações que pode demandar uma sobrecarga excessiva de energia mental no processo de recepção, interpretação e processamento da mensagem. Além disso, mesmo que bem projetada, uma mensagem passará necessariamente por um processo de recepção individual de leitura, no qual cada um, a seu modo, receberá e filtrará a mensagem de forma seletiva, de acordo com seus interesses e motivações momentâneas.

Para comunicar aos usuários com sucesso, a documentação deve fazer mais do que ir ao encontro das necessidades dos usuários, ela deve apresentar informações da mesma forma como os usuários processam as informações. Nós podemos mudar aparências, mas comunicação eficaz não se faz sobre aparências. Comunicação ocorre no nível de suposições, implicações e expectativas. Comunicação eficiente significa determinar e prover respostas para os problemas complexos do mundo real. (Albers, 2005: 5-8).

Enquanto outros tipos de comunicação podem ser bem sucedidos somente por uma apresentação estética adequada, a comunicação técnica requer mais do que isso; ela necessita gerar credibilidade pelo seu conteúdo. Uma produção visual excepcional não substitui eventual falta de conteúdo técnico.

Para entender os motivos disso, consideramos as idéias do arquiteto romano Vitruvius totalmente aplicáveis à comunicação técnica, mesmo tendo sido publicadas há mais de 2000 anos. Vitruvius estabeleceu três condições para uma boa arquitetura: "firmitas, utilitas, venustas", traduzidas do latim por durabilidade / firmeza, utilidade /comodidade e beleza / prazer, respectivamente (apud Mijksenaar, 1997, p. 18). Aplicando os mesmos conceitos para a prática da arquitetura da informação na comunicação técnica, podemos enxergá-la como sendo uma relação entre elementos que envolvem não somente conceitos de beleza, mas também de utilidade, estabilidade e segurança proporcionadas ao usuário da comunicação.

O fato de um material possuir deficiências em sua apresentação estética sendo, porém legível e confiável no que diz respeito ao seu conteúdo, não impede a sua utilidade do ponto de vista da transmissão de informações técnicas. Porém, a recíproca não é verdadeira, e se as deficiências estiverem relacionadas ao conteúdo técnico, não há recursos estéticos que possam esconder essa realidade e criar a mesma confiabilidade que informações técnicas proporcionariam. Mijksenaar (1997:18) explica o motivo disto, citando as seguintes palavras de Henry van de Velde: "beleza é o resultado de clareza e sistemática". O autor defende que beleza é uma consequência de aspectos racionais do material e não uma característica que ocorre de forma independente.

A realidade que constatamos na prática da comunicação técnica é que existe uma dificuldade dos profissionais da comunicação em falar de assuntos técnicos, devido à falta de habilidades e conhecimentos para expô-los. A comunicação técnica requer, para o seu desenvolvimento, a presença de um comunicador de formação mais complexa ou de uma equipe multidisciplinar, já que a atividade de comunicar tecnicamente é bastante abrangente para ser feita por um único profissional. Especialistas em comunicação e especialistas no assunto técnico tratado, trabalhando de forma integrada e procurando, através da parceria, superar as suas limitações, é, em nossa opinião, a forma mais indicada para integrar, de modo equilibrado, os requerimentos de utilidade, satisfação e confiabilidade no design de catálogos técnicos.

\section{O referencial técnico dos catálogos}

A realidade do catálogo técnico encontra-se entre dois referenciais, um instrucional e/ou técnico, o outro publicitário; um com a função de instruir e convencer ética e tecnicamente, o outro de persuadir e convencer comercialmente. No primeiro referencial, estariam os manuais técnicos, voltados ao objetivo de atender as necessidades de um usuário; no segundo, estaria uma ferramenta de publicidade, mais voltada ao objetivo de atender as necessidades institucionais de divulgação de produtos e marcas.

Para o atendimento de sua função técnica, consideramos útil a consideração de Van der Meij, Blijleven e Jansen (2003 129-186) que categoriza os conteúdos de um manual técnico em quatro tipos, segundo a perspectiva pragmática, ou seja, segundo as possíveis reações dos usuários: 1.objetivos, 2.pré-requisitos, 3.ações-reações e 4.estados indesejados. Os objetivos se referem ao estado desejado para o usuário após ele ter feito uso do material. Pré-requisitos são as condições iniciais necessárias para que o usuário alcance o objetivo do material; geralmente se referem ao estado do sistema, às habilidades do usuário e ao seu conhecimento. As ações e reações envolvem o que deve ser feito pelo usuário para alcançar o objetivo principal do material, assim 
como objetivos intermediários. Os estados indesejados são aqueles a serem evitados, porém possíveis de ocorrerem; devem ser previstos através de avisos e de seções referentes à solução de problemas.

Wurman (1991:105) também apresenta uma visão interessante sobre o que seriam boas orientações de procedimentos, quando diz que os seus componentes essenciais são: 1.tempo estimado para a realização de alguma ação indicada; 2.previsão, pistas indicativas de se estar no caminho certo da ação; 3.indicação de erro e sugestão de correções. Este terceiro componente é o que frequentemente falta nas orientações técnicas, sendo, provavelmente, o componente mais essencial.

As colocações acima são totalmente aplicáveis no desenvolvimento do catálogo técnico e da comunicação técnica, de forma genérica. Além delas, existem diretrizes já consagradas por profissionais da comunicação para a criação de bons manuais, entre as quais destacamos: utilização de uma linguagem simples, clara, objetiva; organização das informações em agrupamentos similares de conteúdos e em sequência lógica de procedimentos, bem como o uso adequado de ritmo, que pode ser conseguido por meio da alternação ou variação no emprego de recursos visuais gráficos como tamanho de parágrafos, ênfases para destacar assuntos mais importantes dos secundários, espaços brancos para descansar a vista, etc.

\section{O referencial de comunicação dos catálogos}

Paralelamente à função de transmitir conteúdos técnicos, o catálogo tem a missão de comunicar atributos de marcas, produtos e tecnologias oferecidos por uma organização. Pode, assim, funcionar como uma ferramenta promocional, um instrumento capaz de transmitir aos funcionários, usuários, consumidores, fornecedores e demais parceiros corporativos, valores ligados à organização e colaborar, direta ou indiretamente, com o processo de venda de seus produtos.

Os objetivos promocionais podem ser designados, genericamente, pelos verbos informar, persuadir ou lembrar. De forma simplista poderíamos dizer que, a partir do referencial promocional, os objetivos do catálogo técnico são: informar sobre marcas e produtos, suas possíveis aplicações e modos de funcionamento; persuadir o leitor a mudar sua percepção sobre as marcas e produtos apresentados; lembrar o leitor sobre a existência dos produtos e marcas anunciados no momento da necessidade de aquisição de alguma tecnologia apresentada no material, de modo que eles sejam analisados positivamente em relação aos produtos e marcas concorrentes.

Quando usada convenientemente, a publicidade pode criar ou aumentar as percepções de qualidade de um produto, incentivando, com isso, a lealdade dos clientes e a repetição das compras. Para tanto, é fundamental ao comunicador conhecer o produto que está sendo anunciado, saber de seus benefícios e possíveis defeitos, saber de suas vantagens e desvantagens com relação a produtos concorrentes e saber usar as vantagens para diferenciar e promover a marca em questão. Da mesma forma, é imprescindível saber quem são as pessoas que devem ser atingidas pela comunicação do catálogo técnico; respeitá-las e entender os motivos pelos quais elas comprariam e/ou usariam o produto promovido.

No caso dos catálogos técnicos, entendemos que o comportamento de aceitação ou aquisição de um produto pode ser função da expectativa positiva que o catálogo tem a capacidade de criar em torno dele. Isso pode ser obtido tanto através da oferta de informações técnicas desejadas, como também pela apresentação dos benefícios possíveis de serem alcançados com o uso do produto.

\section{Critérios para análise e avaliação de materiais de comunicação técnica}

Em um estudo de caso envolvendo a comparação entre dois catálogos técnicos de engenharia civil, Schmid (2006) utilizou o referencial teórico de dois profissionais reconhecidos em design, Jorge Frascara e Paul Mijksenaar ${ }^{1}$, para construir modelos e métricas capazes de testar a nova

\footnotetext{
${ }^{1}$ Jorge Frascara, formado pela Escola Nacional de Belas Artes de Buenos Aires, tem trabalhado em publicidade, animação, design editorial, material didático, sinalização e design social. Foi presidente da Icograda e chefe do Departamento de Arte e Design da Universidade de Alberta, Canadá, onde reside atualmente. É autor de vários livros sobre design, dos quais destacamos El diseño de comunicación, edição revisada e estendida de Diseño Gráfico y Comunicación. Paul Mijksenaar é o presidente da Mijksenaar, empresa de design especializada em consultoria e criação 17
} 
versão impressa de um catálogo tradicional no campo do concreto protendido, antecipando a identificação das partes ruins que poderiam eventualmente causar problemas aos principais tipos de usuários envolvidos no manuseio do catálogo - engenheiros, administradores e comunicadores.

Para validar sua proposta de design, ou melhor, de redesign do catálogo tradicional junto à empresa de engenharia, prestadora de serviços especializados no ramo da construção civil, a autora procedeu à análise comparativa das duas versões: a antiga, existente há mais de 25 anos no mercado e utilizada intensamente como referencial técnico em sistemas de protensão até o final de 2006, ano em que a empresa o substituiu pela nova versão, mais alinhada com os princípios visuais do design da informação e, sobretudo, mais completa em relação às recentes conquistas tecnológicas na área específica do concreto protendido.

O objetivo da análise comparativa foi a de fornecer à empresa de engenharia evidências objetivas - aquém, portanto, do gosto pessoal de seus criadores - de melhorias que poderiam ser adotadas na nova versão do catálogo para evitar a reincidência de falhas percebidas no material ultrapassado e, tudo isso, com a segurança de um método comum de análise formal e de conteúdo.

Acreditamos ser útil a exposição de como o referencial teórico dos designers acima mencionados foram transformados e operacionalizados em instrumentos de avaliação de design, pois reconhecemos a dificuldade prática, tanto em âmbito profissional quanto no âmbito acadêmico, de se eleger ou de construir, com grau suficiente de segurança, uma metodologia capaz de evidenciar ao cliente contratante dos serviços de comunicação a qualidade superior da proposta apresentada como solução de comunicação.

É objetivo deste artigo mostrar, ainda que de forma bem sucinta, como os fundamentos de Frascara e de Mijksenaar inspiraram Schmid a conduzir a análise comparativa das duas versões do catálogo nas duas etapas do seu estudo: 1- levantamento quantitativo dos principais elementos visuais existentes na composição de cada versão do catálogo, fundamentado nas reflexões de Frascara sobre os tipos de design ; 2- aplicação de um questionário estruturado a usuários diversos dos catálogos, a respeito de sua usabilidade, ou seja, a respeito de sua utilidade, confiabilidade e satisfação estética, os três eixos de um bom design, segundo Mijksenaar.

Não é nossa pretensão generalizar os métodos propostos neste estudo de caso particular, nem mesmo discutirmos particularidades dos resultados obtidos, mas, antes, destacarmos como alguns referenciais teóricos podem subsidiar operações concretas, e até mensuráveis, de análise e conseqüente avaliação de materiais gráficos de comunicação técnica, evitando, em casos considerados similares, a reinvenção de métodos e a perda desnecessária de tempo e de energia. Reconhecemos, no entanto, que cada caso é um caso e que as práticas que iremos descrever não são receitas prontas; apenas um referencial de consulta, sujeito, ele também, à avaliação de adequação e pertinência.

\subsection{Levantamento quantitativo ordenado por critérios desenvolvidos a partir de Frascara}

Frascara (2006: 121-152) entende o campo do design de comunicação a partir de quatro áreas fundamentais cujos limites se sobrepõem parcialmente no cotidiano profissional: "design para informação"; "design para persuasão"; "design para educação" e "design para administração".

Segundo ele, o design para informação envolve basicamente a organização verbal e visual da informação visando a sua transmissão de forma eficaz e inclui em seu fazer típico os processos de concepção, programação, projeto de produtos como livros, periódicos, sistemas de sinalização, gráficos, diagramas, instruções, mapas e planos, entre os principais representantes desta área.

Com relação ao design para persuasão, o autor defende que:

O design persuasivo é o design de comunicação destinado a influenciar a conduta do público e inclui três linhas fundamentais: publicidade (comercial e não comercial), propaganda (política ou ideológica) e comunicações de interesse social (saúde, higiene, segurança, prevenção de acidentes, etc.). (Frascara, 2006: 130).

Sobre o design para educação, Frascara defende ser uma união de princípios de informação e persuasão apresentados acima, pois a educação busca mudanças de conduta por parte do receptor. Porém, é uma área que oferece ao usuário do produto de design possibilidades de 
interpretação e ação. Os produtos requerem a participação ativa do usuário, o que não ocorre necessariamente no caso da informação.

Por fim, o design para administração faz parte de uma classe distinta, com características especiais que facilitam a percepção de ordem nos produtos de comunicação, através de uma estrutura física específica. Nas palavras do autor, "não implica persuasão, informação ou educação nos sentidos expressados anteriormente, mas contribui para a organização de certas comunicações dentro de sistemas" (Frascara, 2006:146). Envolve, por exemplo, o desenvolvimento dos formulários de uma corporação ou de todo o tipo de material que transmita informações necessárias à sua organização.

A partir das quatro áreas básicas expostas pelo autor como componentes do design gráfico, consideramos que os catálogos técnicos analisados se encaixam principalmente como produtos de:

- design para informação: os catálogos são instrumentos de comunicação técnica e por isso procuram fazer uso do design para expor a informação verbal de forma eficaz e confortável;

- design para persuasão: os catálogos são instrumentos de comunicação de marketing e por isso procuram influenciar sobre a conduta do seu público;

- design para administração: os catálogos são instrumentos de comunicação de informações múltiplas, tanto técnicas, quanto comerciais, e por isso procuram fazer uso de uma estrutura organizada para guiar os usuários no acesso sequenciado e hierarquizado dos diversos níveis de informação.

Apesar dos catálogos também serem produtos de design para educação, uma vez que buscam ensinar o receptor e mudar a sua conduta, não levamos em consideração isoladamente esta opção proposta pelo autor, por acreditar que ela ocorre paralelamente às outras formas de design, unindo-as como um todo. Consideramos que todo material de comunicação técnica é desenvolvido com a intenção de educar seu leitor.

Aplicando esta classificação das áreas/funções fundamentais de Frascara na análise comparativa de catálogos técnicos de engenharia, Schmid (2006) fez um levantamento da quantidade dos principais elementos existentes na composição de cada catálogo, página a página, e classificou cada elemento de acordo com sua função principal na página: ser um elemento "para informação", ou seja, para transmitir essencialmente um conteúdo técnico de engenharia; ser um elemento "para persuasão", para chamar a atenção para a marca da instituição ou para outra informação de natureza promocional; e, finalmente, ser um elemento "para administração", quer dizer, para organizar didática e hierarquicamente os conteúdos.

Schmid identificou nas páginas dos catálogos os seguintes elementos visuais: títulos, subtítulos, rodapés, tabelas, fotografias, desenhos, diagramas e gráficos, blocos de texto, listas de itens, legendas e textos explicativos, recursos de realce de texto, logomarca da empresa, linhas, fios, bordas, fundos de cor ou textura e, até mesmo, áreas brancas ou "de fundo". Estes foram considerados os elementos gráficos básicos da linguagem visual dos catálogos.

Depois da identificação e quantificação de cada elemento, página por página, a autora procedeu à classificação dos mesmos em três tipos de categorias, conforme sua função precípua na página: funcionar como elemento de informação; de persuasão ou de administração (Frascara, 2006, 121-152). Os elementos com qualquer conteúdo técnico sobre o assunto principal foram considerados como componentes de um design para informar. Os demais elementos com algum conteúdo, porém sem ligação direta com a tecnologia principal apresentada pelo catálogo, foram considerados elementos de um design para persuadir, uma vez que eles estão sendo expostos por outros motivos que não o de informação técnica específica sobre o assunto principal do catálogo. E por fim, os elementos de design sem qualquer conteúdo, usados somente para a organização do material e definição do layout da página, foram classificados como produtos de design para administração.

Dessa maneira, Schmid (2006, p.104-117) contabilizou um total de 396 elementos nas 16 páginas do catálogo antigo, $50,5 \%$ dos quais categorizados como elementos para informação; $24,5 \%$ como elementos para persuasão e $25,8 \%$ como elementos para administração. Em relação à versão nova do catálogo, de 32 páginas, Schmid contou 745 elementos, dos quais $35,4 \%$ foram classificados como informação; 22,1\% como persuasão e 42,5\% como administração da leitura.

Verificamos, por esta análise quantitativa, que o primeiro catálogo, o mais antigo, foi desenvolvido com a preocupação principal de informar. A quantidade de elementos de design para informação foi dominadora no catálogo, se comparada com os elementos de design para 
persuasão e administração. A nova versão foi feita com a intenção principal de tornar a apresentação do conteúdo técnico mais didática e mais confortável: apesar de ter o dobro de páginas, a quantidade de informação proporcional diminuiu, o que possivelmente possibilitou o maior peso dos elementos de design para administração, como fios, boxes, áreas brancas, destaques, fotografias ou gráficos maiores, etc., responsáveis pela apresentação "arejada" do conteúdo.

Esta contagem proporcionou uma desconstrução dos dois catálogos e possibilitou saber em que proporção cada um dos dois referenciais fundamentais da comunicação técnica mencionados anteriormente (referencial técnico-informativo e referencial promocional-persuasivo) foi utilizado para construir um equilíbrio. Ainda que o critério de classificação possa ser considerado subjetivo, em uma avaliação comparativa o que importa é a constância, durante toda a análise, dos mesmos critérios de classificação aplicados na categorização de elementos da mesma natureza ou função.

\subsection{Avaliação de usabilidade baseada em critérios desenvolvidos a partir de Mijksenaar}

Em um segundo momento de análise dos catálogos de engenharia, Schmid (2006) elaborou um questionário para avaliar a usabilidade da nova versão impressa do catálogo sobre concreto protendido, junto a três tipos de usuários- engenheiros, administradores e comunicadores- a partir dos conceitos difundidos por Mijksenaar (1997:18-20).

$\mathrm{O}$ autor defende que "design sempre envolve três fatores intrinsecamente relacionados, porém muito de sua proporção relativa pode variar de uma aplicação para outra, que são: durabilidade, utilidade e beleza." (Mijksenaar, 1997:18). A partir disso, o autor relacionou suas idéias às de Vitruvius, já expostas neste trabalho, e desenvolveu um critério de análise para materiais de comunicação, baseado nos seguintes elementos:

- confiabilidade - relacionado à segurança gerada pelo material;

- utilidade - relacionado à aplicabilidade do material;

- satisfação - relacionado à capacidade do material agradar esteticamente.

Figura 1 Modelo de três eixos (Fonte: MIJKSENAAR, Paul.1997:18)

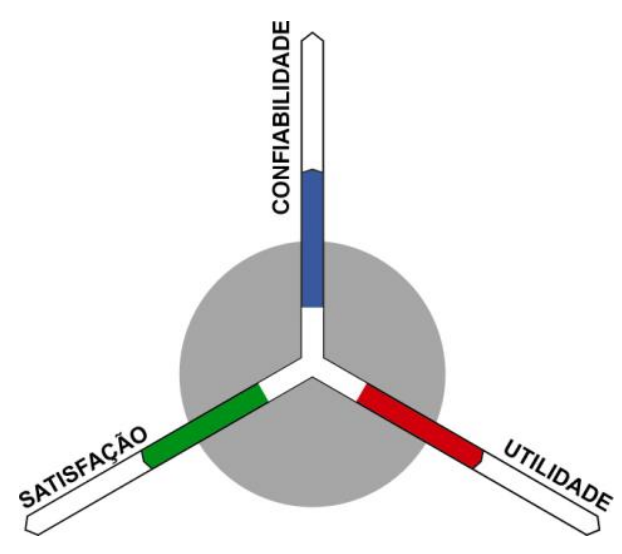

Para avaliar combinações destas características em produtos de design, Mijksenaar estabeleceu um modelo composto por três eixos, ou três termômetros, capazes de mostrar a quantidade de cada elemento existente no produto em avaliação. A figura 1 mostra este modelo, com quantidades equilibradas de satisfação, confiabilidade e utilidade. Um círculo indica um nível médio abaixo do qual o autor não recomenda que bons produtos se localizem. $O$ autor propõe que os eixos comecem de um valor maior que zero e tenham comprimento teoricamente ilimitado - isso porque na sua concepção nenhum dos eixos poderia, em qualquer caso, resultar em zero, ao mesmo tempo em que não existe um nível máximo de sucesso para cada elemento analisado. O modelo consegue, desta forma, indicar uma visão global a respeito da combinação dos requisitos considerados necessários a um bom material de comunicação.

Este modelo de três eixos, embora não tenha sido concebido por seu autor como um método quantificável e, portanto, aplicável a testes de usabilidade, serviu de inspiração para a segunda etapa de análise proposta por Schmid (2006), na qual foram desenvolvidos questionários estruturados para serem aplicados a um número representativo de usuários na detecção de possíveis falhas ou problemas na versão nova do catálogo em questão.

Em seu estudo de caso, Schmid construiu três blocos de questões, cada bloco destinado especificamente a obter dos entrevistados opinião sobre a capacidade de cada catálogo ser um material útil, confiável e agradável. Em cada bloco, um para cada eixo, Schmid propôs um conjunto de frases afirmativas e pediu aos avaliadores que dessem uma nota de 0 a 2 para cada afirmação, conforme seu grau de concordância com o conteúdo da mesma. O cabeçalho do questionário continha a seguinte orientação:

Nesta seção você irá avaliar a (utilidade ou segurança ou satisfação) dos catálogos. Cada afirmação abaixo deve corresponder a uma resposta sua, conforme o seguinte critério: "0" significa não concordo; "1" significa concordo parcialmente; "2", concordo plenamente; "NS", não sei responder. Anote ao lado esquerdo de cada afirmação o valor de sua resposta para o catálogo antigo. Anote ao lado 
direito de cada afirmação o valor de sua resposta para avaliar o catálogo novo. (SCHMID, 2006, p.121122).

Para avaliar a utilidade dos catálogos, por exemplo, foram criadas afirmações do tipo: "O conteúdo apresentado no catálogo possibilita a compreensão dos princípios fundamentais da tecnologia do concreto protendido". Se o avaliador do catálogo antigo, por exemplo, concordasse plenamente com esta afirmação, ele deveria assinalar nota 2 no lado esquerdo da mesma. A mesma operação foi requerida para outras treze afirmações como, p.ex., "O catálogo apresenta condições de uso por usuários novatos quanto por usuários experientes", "É possível entender quais são os passos subsequentes de cada tarefa", "As informações apresentadas oferecem suporte total à sua necessidade de um catálogo sobre concreto protendido" (...) para que engenheiros, administradores e comunicadores entrevistados, de acordo com sua perspectiva profissional, projetassem suas respostas em relação à clareza de conteúdo e ao seu tratamento didático, comparando cada um dos dois catálogos mostrados a eles anteriormente.

Para avaliar a segurança/confiabilidade dos catálogos, foram utilizadas afirmações como " $A$ tecnologia apresentada, seus valores e unidades seguem regulamentações e normas técnicas oficiais adotadas para prática do concreto protendido", "O uso de fotografias e ilustrações colabora para aumentar confiança no conteúdo técnico apresentado", "O conteúdo expõe possíveis consequências técnicas geradas pela não obediência de procedimentos apresentados", "O conteúdo técnico é apresentado no catálogo sem contradições entre textos e imagens", entre outras oito frases. As afirmações relativas a este eixo tinham como objetivo fazer os entrevistados revelarem se a apresentação visual das páginas poderia interferir ou não na confiabilidade do conteúdo transmitido - normalização das informações, indicação de riscos e alertas e apresentação clara de solução de possíveis problemas no uso da tecnologia.

Para avaliar a satisfação visual entre os dois catálogos, os entrevistados tinham que verificar o grau de sua concordância em relação a afirmações do tipo "A capa do catálogo atrai a atenção para a leitura do conteúdo interno", "Em cada página, existem indicações práticas para o usuário saber qual é o assunto apresentado", "A quantidade de ilustrações é adequada para mostrar a importância da tecnologia do concreto protendido e algumas de suas aplicações”, por exemplo, para que os dois catálogos fossem julgados quanto à leiturabilidade, aparência e atratividade do material.

Ao todo, o questionário foi composto por 40 frases afirmativas que receberam notas de 0 a 2 de cada um dos 14 avaliadores $^{2}$ e para cada um dos dois catálogos testados. A média aritmética das notas atribuídas para cada afirmação gerou gráficos que mostraram a posição relativa de cada catálogo testado nos quesitos utilidade, segurança e satisfação (SCHMID, 2006, p.138-141). A versão nova do catálogo, por exemplo, mostrou que a maior parte das afirmações recebeu médias variando de 1 a 2 ( alta concordância com a positividade das afirmações) enquanto o catálogo antigo mostrou oscilações mais fortes para baixo, sobretudo no quesito satisfação, onde a maior parte das afirmações recebeu médias de 0 a 1, demonstrando concordância parcial ou quase nula dos usuários com a positividade das afirmações.

Tal método foi importante para se ter uma idéia da porcentagem de utilidade, confiabilidade e satisfação que cada profissional tinha em mente considerando-se um "catálogo ideal" e a comparação deste catálogo ideal à realidade de cada um dos dois catálogos de engenharia apresentados no estudo.

\section{Considerações finais}

Estudar a comunicação técnica do ponto de vista do design da informação nos permitiu avaliar que sua prática não é tarefa simples. Porém, a interseção das duas disciplinas pode resultar em uma integração positiva e equilibrada entre o conhecimento intelectual inerente a uma informação técnica e a representação visual advinda de um produto de comunicação.

As considerações teóricas nos permitiram conhecer algumas barreiras capazes de interferir no processo da comunicação técnica, podendo comprometer o seu resultado de forma desastrosa. Porém, através do estudo de elementos do design da informação, pudemos também detectar recursos diversos para se combater estas barreiras, destacando, inclusive, a possibilidade da construção de métodos e métricas, a partir de referências teóricas, para a análise comparativa de

\footnotetext{
${ }^{2}$ A quantidade de usuários avaliadores e os princípios de usabilidade foram baseados em Jakob Nielsen, considerado um dos profissionais mais respeitados no assunto. Ele desenvolveu vários métodos de análise de usabilidade, incluindo a avaliação heurística que serviu de base para o desenvolvimento do questionário em questão.
} 
materiais técnicos, no lugar de avaliações fortemente subjetivas, tão comuns na hora de aprovação de projetos pelos clientes contratantes dos serviços de comunicação.

A abordagem que fizemos ao catálogo técnico procurou considerá-lo como um instrumento de comunicação destinado a três objetivos principais: comunicar, através de técnicas de comunicação; informar, através da transmissão de conteúdos técnicos relevantes; persuadir, através da transmissão de interesses comerciais por parte da corporação emissora do material.

Através da desconstrução das páginas dos catálogos, método desenvolvido a partir do referencial teórico de Frascara, foi possível analisá-los como produtos de design e obter uma visão global sobre o seu aspecto gráfico, na tentativa de entender que elementos o primeiro material analisado (catálogo tradicional) tinha de tão negativo, que causava a insatisfação a seu respeito, e quais eram os positivos, que resultaram na sua utilidade prolongada, até 2006 , quando foi substituído por uma versão atualizada.

O levantamento quantitativo de elementos gráficos existentes em uma página impressa e categorizados segundo sua função primordial na página é um método que pode auxiliar criadores - designers e comunicadores - a terem lucidez e objetividade quanto à adequação ou não de determinado design a uma estratégia assumida de comunicação. Trata-se de uma ferramenta de análise e avaliação para o produtor/codificador de mensagens.

A aplicação do questionário, por sua vez, pretendeu mostrar a aceitação dos catálogos e a eficiência da comunicação, considerando seus usuários típicos e as qualidades que todo bom produto de design deve ter segundo o critério Mijksenaar - utilidade, confiabilidade e satisfação estética - em doses equilibradas, conforme os objetivos do material em teste. Esse recurso mostrou os pontos que ainda poderiam ser melhorados na nova versão do catálogo, tomando-se a opinião de usuários como estratégia de criação colaborativa. Trata-se de uma ferramenta complementar que auxilia os criadores a entender melhor o ponto de vista do usuário, suas opiniões e seus modos de avaliação.

Estes dois métodos operacionalizados a partir das contribuições de reconhecidos designers e professores de design, embora brevemente aqui descritos, fornecem argumentos mais seguros à apreciação crítica de produtos impressos de comunicação técnica do que o simplesmente "gosto ou não gosto, mas não sei bem o porquê".

Conforme expusemos nas considerações teóricas, é desejável a um material de comunicação que a sua aparência esteja em harmonia com a expectativa da sua audiência. Isso possivelmente só ocorre com o conhecimento prévio, por parte do comunicador, das características da audiênciaalvo da comunicação. E este conhecimento será tanto mais profundo, quanto mais o comunicador dominar o assunto tratado no material de comunicação. Percebemos, assim, que a eficiência da comunicação técnica não está relacionada somente à aplicação de técnicas da comunicação a um conteúdo específico, nem ao domínio desse conteúdo, mas aos dois fatores caminhando juntos.

Conhecer profundamente a informação a ser veiculada, os pontos fortes e fracos dos "atores" envolvidos e o meio onde a comunicação será inserida e aliar esse conhecimento a métodos de análise e avaliação do material concebido, antes mesmo de ser produzido, é um requisito básico para a atuação do comunicador técnico.

\section{Referências}

Albers, M. J. 2005. The key for effective documentation: answer the user's real question. Usability Interface, v. 11, n. 4, p. 5-8. Disponível em <http://www.stcsig.org/usability>.

Cliff, S.1994. The best in catalogue design. Mies: Rotovision.

Frascara, J. 2005. Diseño gráfico y comunicación - 6. ed. Buenos Aires: Infinito.

Mijksenaar, P. 1997. Visual function: an introduction to information design. Nova lorque: Princeton Architectural Press.

Nielsen, J.; Mack, R. L. Usability inspection methods. Nova lorque: John Wiley \& Sons, 1994.

Parry, J. 1976. Psicologia da comunicação. São Paulo: Cultrix.

Rosenfeld, L.; Morville, P.1998. Information architecture for the World Wide Web. Sebastopol : O'Reilly\&Associates.

Schmid, M.R.L. 2006. Comunicação e informação no design de catálogos técnicos: um estudo comparativo de catálogos de engenharia. Dissertação (mestrado). Programa de Pós-graduação 
em Ciências da Comunicação. Escola de Comunicações e Artes da Universidade de São Paulo.

Van der Meji, H.; Blijleven, P.; Jansen, L. What makes up a procedure? In: Albers, M. J.; Mazur, B.(Org.). 2003. Content and complexity: information design in technical communication. Londres: Lawrence Erlbaum Associates.

Wurman, R. S. 1991. Ansiedade de informação: como transformar informação em compreensão. Tradução de Virgílio Freire. São Paulo: Cultura Editores Associados.

\section{Sobre os autores}

Sandra M.R.de Souza é doutora em Ciências da Comunicação pela ECA-USP, onde atua como docente no Programa de Pós-Graduação e na graduação em Publicidade e Propaganda. Coordena o GEIC, Grupo de Estudos da Imagem em Comunicação.

<smrdsouz@usp.br><smrdsouz@bol.com.br>

Maria Regina L. Schmid é mestre em Ciências da Comunicação pela ECA-USP e pesquisadora do GEIC. Atua como engenheira, designer e docente em cursos de graduação de Design e Arquitetura.

<ginadesign@ginadesign.com.br> 